\title{
Caso clínico de Elefantiasis Verrucosa
}

\author{
Elephantiasis Verrucosa, clinical case
}

\begin{abstract}
Verónica Castro Bocanegra ${ }^{1}$, José Salcedo Hurtado ${ }^{2}$
${ }^{1}$ Programa de Instrumentación Quirúrgica, Corporación Universitaria Rafael Núñez. Cartagena, Colombia 2Programa de Medicina, Corporación Universitaria Rafael Núñez. Cartagena, Colombia veronica.castro@curnvirtual.edu.co jguille68@hotmail.com
\end{abstract}

\section{RESUMEN}

Se reporta caso de paciente femenino de 29 años de edad con diagnóstico de elefantiasis verrucosa en miembro inferior izquierdo complicada con una necrosis dérmica severa y sepsis de tejidos blandos, con aproximadamente un año de internación. Se describen los parámetros clínicos, radiográficos y plan de tratamiento. Lo relevante de este caso radica en lo infrecuente de esta patología, las complicaciones presentadas en la paciente y lo satisfactorio del tratamiento consistente en el manejo multi e interdisciplinario con el apoyo con insumos de tecnología y técnicas avanzadas en el manejo de heridas e intervención nutricional especializada, que permitió el salvamento de una extremidad cuyo tejido blando se encontraba en un $90 \%$ necrosado.

Palabras Clave: Elefantiasis, verrucosa, insuficiencia, venosa, sistema de presión negativa, matriz dérmica.

\begin{abstract}
We report a 29-year-old female patient diagnosed with verrucous elephantiasis in the lower left limb complicated with severe dermal necrosis and soft tissue sepsis, with approximately one year of hospitalization. Clinical, radiographic and treatment plan parameters are described. The relevance of this case lies in the infrequent of this pathology, the complications presented in the patient and the satisfactory treatment consistent with multi and interdisciplinary management with support with technology inputs and advanced techniques in wound management and specialized nutritional intervention that allowed the Salvage of a limb whose soft tissue was $90 \%$ necrosed.
\end{abstract}

Keywords: Elephantiasis, warty, failure, venous, negative pressure system, dermal matrix 


\section{INTRODUCCIÓN}

La elefantiasis es definida como un aumento exagerado de algunas partes del cuerpo aunque generalmente son los miembros inferiores los más afectados, lo que recuerda la de los elefantes. Se origina como resultado de diversas enfermedades obstructivas del sistema linfático, por la obstrucción permanente de los linfáticos principales, esto causa el agrandamiento gradual, dureza, pliegues y fistulas de la piel y tejido celular subcutáneo de tejidos adyacentes (1).

Muchas veces esta patología va acompañada con insuficiencia venosa crónica periférica puesto que se presenta una disminución del flujo sanguíneo en los vasos sanguíneos periféricos.

Existen diversos subtipos de elefantiasis. La elefantiasis filariasis es la forma más presentada en áreas tropicales y subtropicales, y se produce como resultado de un bloqueo a nivel linfático por vermes parasitarios endémicos. Y la elefantiasis no filariásica está involucrada con casos congénitos hereditarios, relacionados a la enfermedad de Milro y por último, la elefantiasis verrucosa nostras (EVN) que comprende los casos de linfedema crónico no filariásico tanto de causa infecciosa como no infecciosa (2).

Según la Organización Mundial de la Salud (OMS), en su nota descriptiva del mes de marzo 2017, existen unas 947 millones de personas en 54 países amenazados por la filariasis linfática. Mientras que la cifra en el año 2000, era de más de 120 millones de personas infectadas y de ellos unos 40 millones se encontraban desfiguradas e incapacitadas (3).

"La EVN es una condición crónica y progresiva, que se caracteriza clínicamente por la tumefacción de la extremidad afectada con fibrosis de la dermis y del tejido subcutáneo. Los cambios cutáneos característicos incluyen hiperqueratosis, papilomatosis y lesiones verrugosas" (4-5).

En su patogénesis juegan un papel protagónico el linfedema crónico, las infecciones, la cirugía, la radioterapia, la obstrucción neoplásica, el trauma y la obesidad. Sin tratamiento los cambios cutáneos progresan lentamente con el crecimiento desproporcionado y causan deformidad de la extremidad afectada (6). Los principios del tratamiento se enfocan en restaurar la función de los miembros afectados y mejoras visibles estéticamente; antibioticoterapia para la infección sobreaguda, soporte nutricional para control de peso y tratamiento quirúrgico con desbridamiento en caso necesario de resección de las lesiones.

\section{CASO CLINICO}


Paciente de sexo femenino de 29 años de edad, sin alergias conocidas a fármacos, con antecedentes de elefantiasis desde su nacimiento presenta aumento de volumen en extremidad del lado izquierdo. Su condición sociodemográfica previa al ingreso, se trata de una paciente casada, con dos hijos menores de 15 años proveniente de área urbana, estrato 3 , que convive con su pareja e hijos y perteneciente a régimen contributivo. Es una paciente colaboradora, orientada en las tres esferas, buena expresión oral, animada ante pronóstico y buena actitud ante la vida.

La paciente es atendida primeramente en una Institución Proveedora de Servicios de Salud (IPSS) de IV nivel de atención de la ciudad, donde le realizan paraclínicos complementarios que evidencian alteraciones en la coagulación y signos clínicos y paraclínicos de deshidratación. Inician reanimación con cristaloides y destrozados por hipoglucemia severa con previa colocación de CVC derecho. En esta IPSS deciden trasladarla a otra IPSS de las mismas características por terminación de contrato con su Entidad Promotora de Servicios de Salud (EPSs), con el diagnóstico de sepsis severa de foco a determinar.

La paciente es trasladada a la otra IPSS donde se realiza su ingreso y nueva valoración por medicina general y se remite a cirugía vascular periférica. En la exploración física se destaca dermatosis diseminada a extremidades superiores e inferiores del lado izquierdo constituida por deformidad y aumento de volumen de las extremidades y verrugosidades, y ulceraciones cubiertas con doble vendaje elástico, emanando un olor pútrido (ver imagen 1 y 2 ).

Imagen 1 y 2. Fotografia de Miembro Inferior Izquierdo del paciente donde se observa aumento de tamaño del miembro y necrosis de los tejidos.
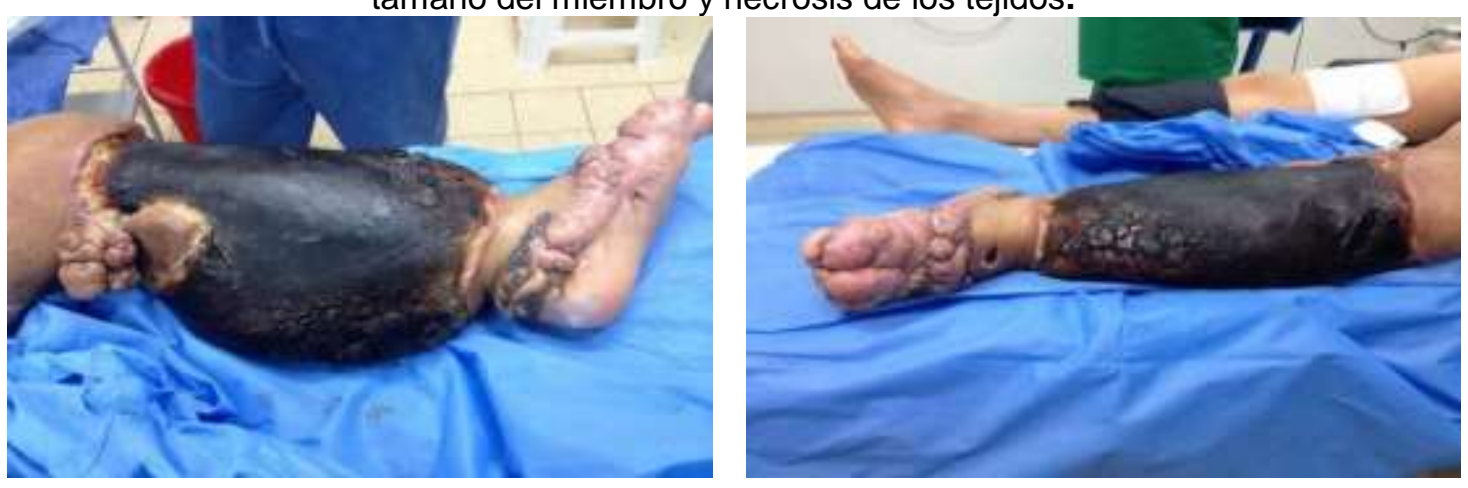

Se define diagnóstico de elefantiasis verrugosa complicada con necrosis e infección severa de tejidos blandos en miembro inferior izquierdo y se ingresa a la unidad de cuidados intensivos con monitoria cardiaca continua por taquicardia, taquipnea leucopenia, con compromiso multi-sistémico y acidosis metabólica; oxigeno con máscara, catéter venoso central, edema en miembro superior izquierdo, escara sacra grado II, genitales hipertroficos y miembro inferior izquierdo asimétrico hipertrófico con múltiples tumultaciones y con alto riesgo para la formación de ulceras por presión.

Se trata con antibioticoterapia de amplio espectro, reanimación con cristaloides (a fin de garantizar perfusión tisular por mejoría de presiones de llenado con el fin de disminuir niveles de hiperlactatemia), controles paraclínicos y radiografía de tórax para escala de ingreso, protección gástrica y vigilancia estricta con monitorización en Unidad de 
Cuidados Intensivos (UCI). A las dos horas de ingreso a UCI presenta signos de estrés respiratorio por lo cual requiere de soporte ventilatorio e intubación orotraqueal previa a secuencia de sedoanalgesia y relajación muscular.

En radiografía de tórax se identifica silueta cardiaca de tamaño normal, arco aórtico sin alteraciones, sombras en base de hemitorax derecho por opacidades alveolares sin descartar presencia de derrame pleural, reja costal y demás estructuras óseas sin alteraciones.

La paciente se estabiliza y 17 días después de su internación en $\mathrm{UCl}$, es valorada por Cirugía General (Cirujano de Heridas Complejas), Ortopedia y Cirugía Vascular Periférica. Se decide en junta médica, por edad de la paciente y el impacto social y familiar, intentar el programa de salvamiento de extremidad según hallazgos intraoperatorios; programar para cirugía de Resección o Desbridamiento de tejido necrótico afectado vs amputación del miembro si había compromiso de tres de los cuatro componentes vitales del miembro (piel, vasos arteriales y linfáticos, sistema muscular y óseo). Durante el acto operatorio se verifica viabilidad del miembro y se decide realizar desbridamiento quirúrgico y preparación del lecho cruento para una eventual reconstrucción, e inicia el uso de una técnica avanzada para el manejo de la herida consistente en terapia de presión negativa (ver imagen 3).

Imagen 3. Fotografía del Sistema de presión negativa en la primera intervención.

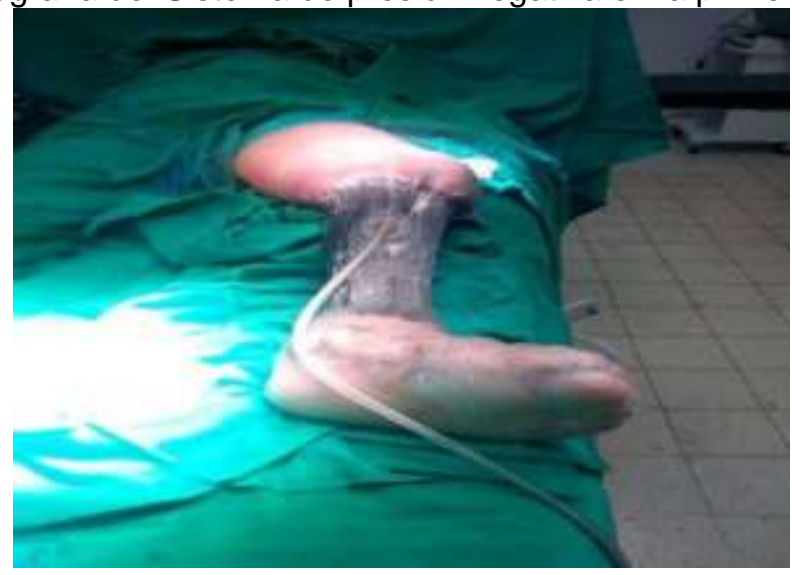

Posterior a la intervención quirúrgica se programó por un periodo de tres meses, cada ocho días, lavado más desbridamientos secuenciales con recambio del sistema para inducir tejido de granulación permaneciendo en $\mathrm{UCl}$ con tratamiento de antibióticos de amplio espectro y vigilancia estricta con monitorización por sepsis generalizada e intervención nutricional especializada dado al alto gasto metabólico y consumo de proteínas de la paciente tanto por su patología de base como por el uso de la Terapia de Presión Negativa y los Desbridamientos quirúrgicos (ver imagen 4 y 5).

Pasados estos tres meses, se realizó desbridamiento de tejidos profundos mayor del $80 \%$ de la pierna izquierda, se decide iniciar reconstrucción de los tejidos blandos dado el estado de granulación óptima del lecho de la herida en la paciente, se solicita la consecución de una matriz dérmica integrada (dos láminas de 20×25 cms - Dermis 
Sintética) para reconstruir la dermis y posteriormente cubrir el lecho con injerto libre de piel, se logra así una reconstrucción total de las diferentes capas de la piel. Esto se realizó en un periodo de cuatro semanas.

Imagen 4 y 5. Fotografia de Miembro Inferior Izq en recambio de sistema y con tejido de granulación.
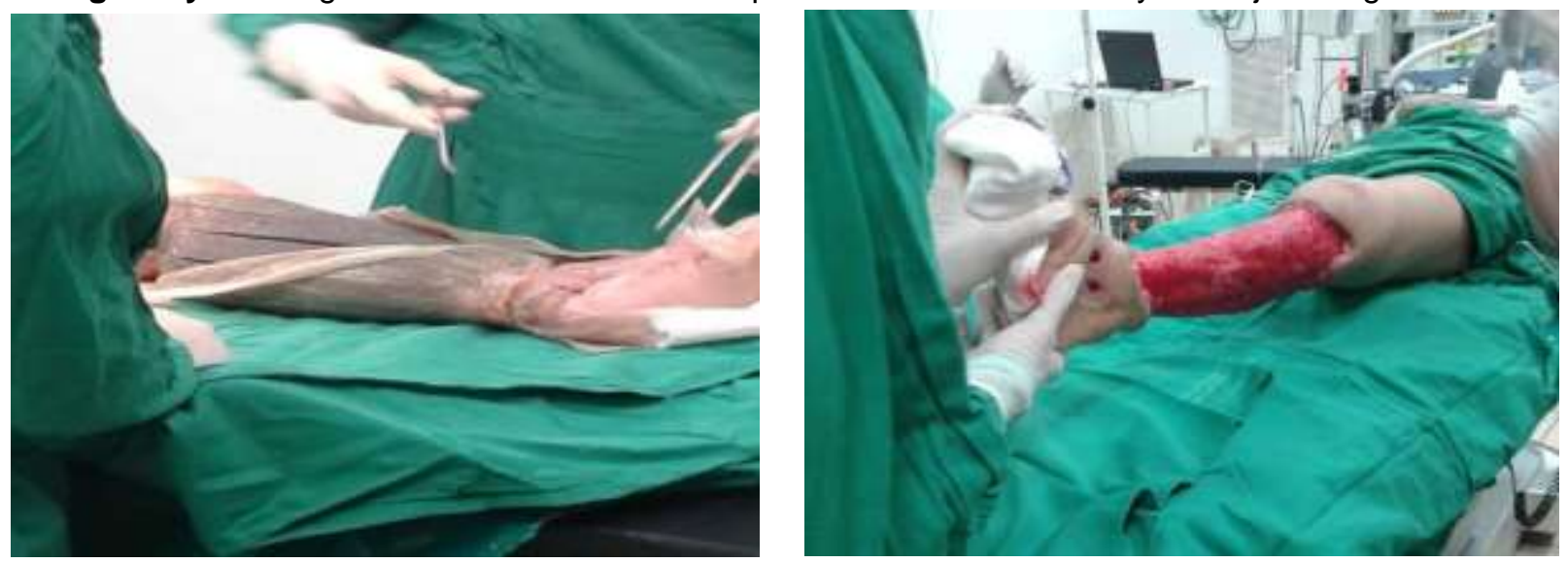

Posterior a ello, se le realizó en conjunto con la especialidad de cirugía plástica un injerto de piel tomado de una zona no afectada (Muslo contralateral), para cubrir el lecho de la herida, ubicado en el miembro inferior izquierdo (injerto libre parcial de piel $20 \%$ de la superficie corporal autólogo mallado) (ver imagen 6 y 7 ).

Imagen 6 y 7. Fotografia de Miembro Inferior Izq con matríz dermica integrada e injerto libre parcial de

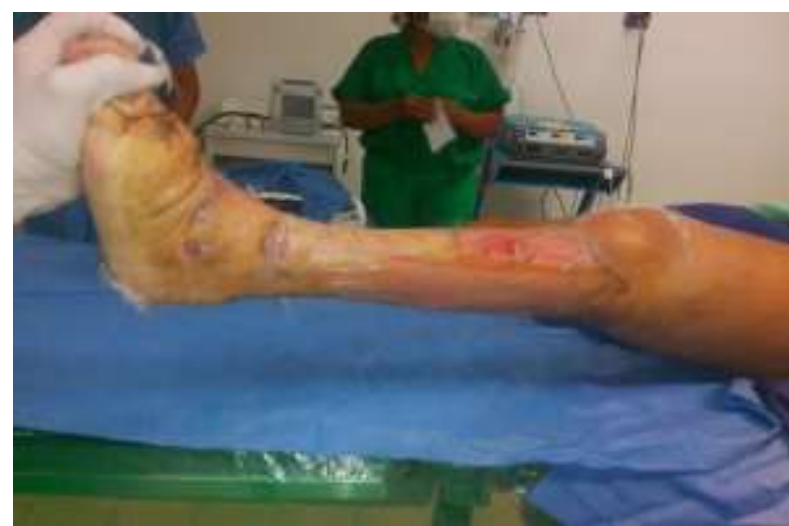
piel.

La paciente presentó buena evolución, después de aproximadamente un año de internación. Continuó con controles ambulatorios y atención en casa por Equipo de Heridas Complejas, presenta movilidad en los miembros y es integrada a su vida familiar y social.

\section{DISCUSIÓN}

La Elefantiasis se puede desarrollar como resultado de un linfedema crónico. Dependiendo de la cronicidad y gravedad, los pacientes que la padecen presentan extremidades excesivamente agrandadas y desfiguradas, que se caracterizan por una piel engrosada y fibrótica (7). 
La característica inicial es la aparición de una piel dura que avanza a una apariencia verrugosa. Posteriormente se ulcera y se forman costras que complican la lesión. La parte afectada se puede colonizar por bacterias, necrosis del tejido y olor fétido (8).

El diagnóstico diferencial de la elefantiasis verrucosa es amplia e incluye la filariasis linfática, cromoblastomicosis, linfedema, lipodermatoesclerosis, papilomatosis y carcinoma de piel. El diagnóstico se basa en la anamnesis y la exploración física. En ocasiones se requiere una biopsia de tejido para descartar tumoraciones malignas y el uso de ayudas diagnósticas imagenológicas como la tomografía axial computarizada, resonancia magnética, linfangiografía y linfoescintigrafía pueden ser muy útiles.

El tratamiento de la EVN es complicado y los resultados no son muy satisfactorios. Inicia con terapias conservadoras como masajes manuales y mecánicos para reducir el edema y la infección, vendaje elástico y la administración de antibióticos y diuréticos; y como última opción el tratamiento de desbridamiento quirúrgico puede ser exitoso (9).

El profesional de la salud que atiende a este tipo de pacientes debe indagar las causas subyacentes de la obstrucción linfática y prevenir las complicaciones asociadas. Reducir al mínimo la inflamación y restaurar la funcionalidad de la extremidad afectada también son muy importantes para aliviar el estrés de los médicos, familiares y pacientes (10), quienes deben reconocer la condición inusual en su etapa inicial para evitar deformaciones y deterioro de la extremidad afectada.

La elefantiasis verrucosa es una patología que requiere múltiples cuidados, desde la concepción física y psicológica puesto que afecta a los hábitos sociales, familiares y personales de quien la padece, así como la concepción patológica que en sí misma conlleva.

En el caso de esta paciente se presenta una condición patológica congénita que con los cuidados necesarios, al conocer la historia natural de la enfermedad, pudo haberse manejado desde el nivel de baja complejidad con atención primaria (prevención y promoción de la salud). Se debe enfatizar en la necesidad de una atención preventiva para este tipo de pacientes que mantenga en alerta la aparición de complicaciones cutáneas (complicaciones de tipo blando y tipo duro).

Favorablemente, la decisión de tratamiento tomada por el equipo interdisciplinar médico y quirúrgico del caso en cuestión, fue la más acertada, puesto que permitió el salvamento de una extremidad cuyo tejido blando se encontraba en un $90 \%$ necrosado.

Se continúa en el trabajo de rehabilitación, reintegro a las labores cotidianas y la prevención de la discapacidad, para mejorar de esta manera la calidad de vida de la paciente.

\section{BIBLIOGRAFÍA}


1. Lozano González Y, González Velásquez E. Elefantiasis. A razón de un caso.

Rev méd electrón [Seriada en línea] 2009; 31(3). Disponible en URL:http://www.revmatanzas.sld.cu/revista\%20medica/año\%202009/vol3\%202009/tema16.htm [con sulta: Abril 25 de 2016]

2. Simon Llanes J, Col Villar I, Tamarit Frances C.Elefantiasis Verrucosa nostras en paciente afectado de trastorno depresivo mayor. Rev. Semergen. 2012; 38(8):526-529.

3. Organización Mundial de la Salud (OMS). Filiarisis linfática. Centro de prensa. Disponible en URL: http://www.who.int/mediacentre/factsheets/fs102/es/ [consulta: Julio 7 de 2017]

4. Boyd J, Sloan S, Meffert J. Elephantiasis nostrum verrucosa of the abdomen: clinical results with tazarotene. J Drugs Dermatol. 2004; 3: 446-8.

5. Schissel DJ, Hivnor C, Elston DM. Elephantiasis nostras verrucosa. Cutis. 1998; 62:77-80.

6. Vásquez, L. Molina, V. Arroyave, J. Arredondo, M. Arango, A. Elefantiasis verrucosa nostra tratada con tazaroteno tópico. Rev Asoc Col Dermatol. 2009; 17(1): 54-56.

7. Fredman R, Tenenhaus M. Elephantiasis Nostras Verrucosa. Eplasty. 2012; $12: i c 14$.

8. Price, E. The management of endemic (non - filiarial) elephantiasis of the lower legs. Trop doctor. 1975;5:70-5

9. Polat, M. Sereflican, B. A Case of Elephantiasis Nostras Verrucosa Treated by Acitretin. J Drugs Dermatol. 2012; 11(3):402-405.

10. Yih Liaw, F. Fu Huang. Ch. Cheng Wu, Y. Yao Wu, B. Elephantiasis nostras verrucosa. Swelling with verrucose appearance of lower limbs. Canadian Family Physician. 2012; 58: 551-553. 